\title{
Proof-of-Concept of a Quasi-2D Water-Quality Modelling Approach to Simulate Transverse Mixing in Rivers
}

\author{
Pouya Sabokruhie ${ }^{1}$, Eric Akomeah ${ }^{2}$, Tammy Rosner ${ }^{3}$ and Karl-Erich Lindenschmidt ${ }^{4, *}$ \\ 1 Global Institute for Water Security, University of Saskatchewan, 11 Innovation Boulevard, Saskatoon, \\ Saskatchewan, S7N 3H5, Canada; p.sabokruhie@usask.ca \\ 2 Water Security Agency, 111 Fairford Street East, Moose Jaw, Saskatchewan, S6H 7X9, Canada; \\ eric.akomeah@wsask.ca \\ 3 Four Elements Consulting Ltd., 1012 18th Ave. SE, Calgary, Alberta, T2G 1L6, Canada; \\ tammy.rosner@Fourelementsconsulting.ca \\ 4 Global Institute for Water Security, University of Saskatchewan, 11 Innovation Boulevard, Saskatoon, \\ Saskatchewan, S7N 3H5, Canada; karl-erich.lindenschmidt@usask.ca \\ * Correspondence: karl-erich.lindenschmidt@usask.ca; Tel.: 001 (306) 966-6174
}

\begin{abstract}
A quasi-two-dimensional (quasi-2D) modelling approach is introduced to mimic transverse mixing of an inflow into a river from one of its banks, either an industrial outfall or a tributary. The concentrations of determinands in the inflow vary greatly from those in the river, leading to very long mixing lengths in the river downstream of the inflow location. Ideally, a two-dimensional (2D) model would be used on a small scale to capture the mixing of the two flow streams. However, for large-scale applications of several hundreds of kilometres of river length, such an approach demands too many computational resources and too much computational time, especially if the application will at some point require ensemble input from climate-change scenario data. However, a one-dimensional (1D) model with variables varying in the longitudinal flow direction but averaged across the cross-sections is too simple of an approach to capture the lateral mixing between different flow streams within the river. Hence, a quasi-2D method is proposed in which a simplified 1D solver is still applied but the discretisation of the model setup can be carried out in such a way as to enable a 2D representation of the model domain. The quasi-2D model setup also allows secondary channels and side lakes in floodplains to be incorporated into the discretisation. To show proof-of-concept, the approach has been tested on a stretch of the lower Athabasca River in Canada flowing through the oil sands region between Fort McMurray and Fort MacKay. A dye tracer and suspended sediments are the constituents modelled in this test case.
\end{abstract}

Keywords: lower Athabasca River; Oil Sands Region; quasi-2D modelling; Water-Quality Analysis Simulation Program (WASP); water-quality modelling

\section{Introduction}

\subsection{Background}

Much of the process water from oil sands surface mining operations is recycled and managed in tailing ponds. However, the capacity for storage is approaching unmanageable and unsustainable levels; hence, some release of treated process water into the Athabasca River is anticipated as early as 2025 [1]. The release of treated process water may pose a risk to aquatic species and to humans who harvest and consume these species, in particular fish. Therefore, effective models to describe the transport and fate of oil sands related substances are required [2]. These substances can be transported downstream and deposited in Lake Athabasca and the Peace-Athabasca-Delta (PAD); in addition, secondary channels and lakes within the floodplain along the lower river reach may also trap released sediment and associated constituents. An important objective of this research is to determine the fate of such effluent within these features using computer modelling. 


\subsection{Water-quality modelling}

The development of complex three-dimensional integrated hydrodynamic, sediment transport, and water quality models has been proposed to characterize the transport and fate of sediment and associated constituents in the lower Athabasca River, advocated by several researchers and government agencies [2]. However, the implementation of complex modelling frameworks may not be advantageous for many reasons, including cost, the time required to develop the framework, and lengthy model simulation times. Additionally, model complexity can obfuscate rather than elucidate key processes, and both overly complex and overly simple models can have reduced reliability.

We propose using the Water Quality Analysis Simulation Program (WASP) to develop a model to characterize the fate and transport of sediment and associated constituents within the lower Athabasca River. WASP is a dynamic compartment-modelling program for aquatic systems, including both the water column and the underlying benthos. Its representation of sediment and material kinetics is more sophisticated than other commonly used models. WASP is a widely used framework for developing site-specific models for simulating toxicant concentrations in surface waters and sediments over a range of complexities and temporal and spatial scales. WASP has an advanced toxicant module that includes representation of a range of solids classes, with individual physical and chemical characteristics. Solids classes can be organic materials (e.g. plankton, algae, detritus) or inorganic (e.g. sand, silt, clay).

\subsection{Quasi-two-dimensional modelling}

This paper describes a unique quasi-two-dimensional representation of river hydraulics that is particularly suited to the application of the WASP model to accurately represent the configuration of the lower Athabasca River with a high level of computational efficiency. In the current study, we introduce a novel approach to modelling transverse mixing in a river with secondary channels and side lakes to study the water quality along the area of the Athabasca River with extensive oil sands development.

To show proof-of-concept, the domain modelled in this study is only a short stretch of $15 \mathrm{~km}$. It is part of a larger system (>200 km) that is to be modelled in the future, with additional outfalls and sensitive depositional areas (e.g. secondary channels and side lakes). In order to maintain short computational times, a one-dimensional (1D) modelling approach is necessary. However, the transverse mixing along the river requires modelling with at least a two-dimensional (2D) representation, especially since the lengths of complete mixing along this river are relatively long $(>100 \mathrm{~km})$. Hence, the use of a quasi-twodimensional (quasi-2D) approach is proposed, in which flow is simulated in 1D, but in such a way to allow a 2D discretisation of the domain.

Quasi-2D water-quality modelling has been carried out in the past for other applications. For off-channel storage facilities (polders) along the Elbe River in Germany, Lindenschmidt et al. [3] modelled dissolved oxygen and nutrient dynamics for various flow regimes (low, medium, high (flood) flows). Deposition of sediments and heavy metals in the off-channel storage basins was also captured using the quasi-2D method [4-6]. The quasi-2D approach has also been used to capture flows between main river channels and their floodplains, in particular through dike breaches [7] and capping flood peaks using side-channel storage [8-9]. Flow between the Mekong River and its delta [10] and between the Po River and a portion of its floodplain [11] were also simulated using quasi-2D models. Sediment transport was also included in a quasi-2D model of the Rhine River's main channel and floodplain [12]. In this study, we extend the quasi-2D approach to model transverse mixing in rivers.

\subsection{Objectives}

The objectives of this study are to: 
1. Develop a quasi-2D modelling approach to characterise transverse mixing of two water streams of different sediment concentrations.

2. Quantify the sediment transport along the lower Athabasca River with a secondary channel and side lake connected hydraulically to the river's main stem.

3. Assess the role of drawing on the output of additional models to complement the implementation of models with different complexity and spatial scale.

\section{Site description}

The Athabasca River is a northern river (ice-covered in winter) in western Canada that originates on the eastern slopes of the Rocky Mountains and flows approximately $1500 \mathrm{~km}$ in a north-easterly direction to empty into Lake Athabasca. It is the longest unregulated river in Alberta. For the last $80 \mathrm{~km}$, the river flows through the Athabasca Delta. The Athabasca Delta is part of the larger Peace-Athabasca Delta (PAD), which is the largest inland delta in North America. The PAD is an important ecosystem for many aquatic and terrestrial plant and animal species, and the area has been named both a Ramsar and UNESCO World Heritage site. From a human perspective, the PAD is an important social, cultural and economic entity for many of the Aboriginal communities in the area. Many conservation efforts have been carried out to maintain the ecological integrity of the aquatic and terrestrial systems.

Referring to Figure 1, the average discharge at the Water Survey of Canada (WSC) gauge at Embarras (gauge 07DD001 - Athabasca River at Embarras Airport), which is approximately $80 \mathrm{~km}$ upstream of the PAD, is around $850 \mathrm{~m}^{3} / \mathrm{s}$. The total catchment area draining at the same gauge is approximately 156,000 $\mathrm{km}^{2}$. Much of the basin's land use consists of forests $(89 \%)$ with some agricultural lands $(8 \%)$. The basin is sparsely populated ( $\approx 200,000$ inhabitants), with the population concentrated in a few urban centres, which release effluent from municipal wastewater treatment plants into the river.

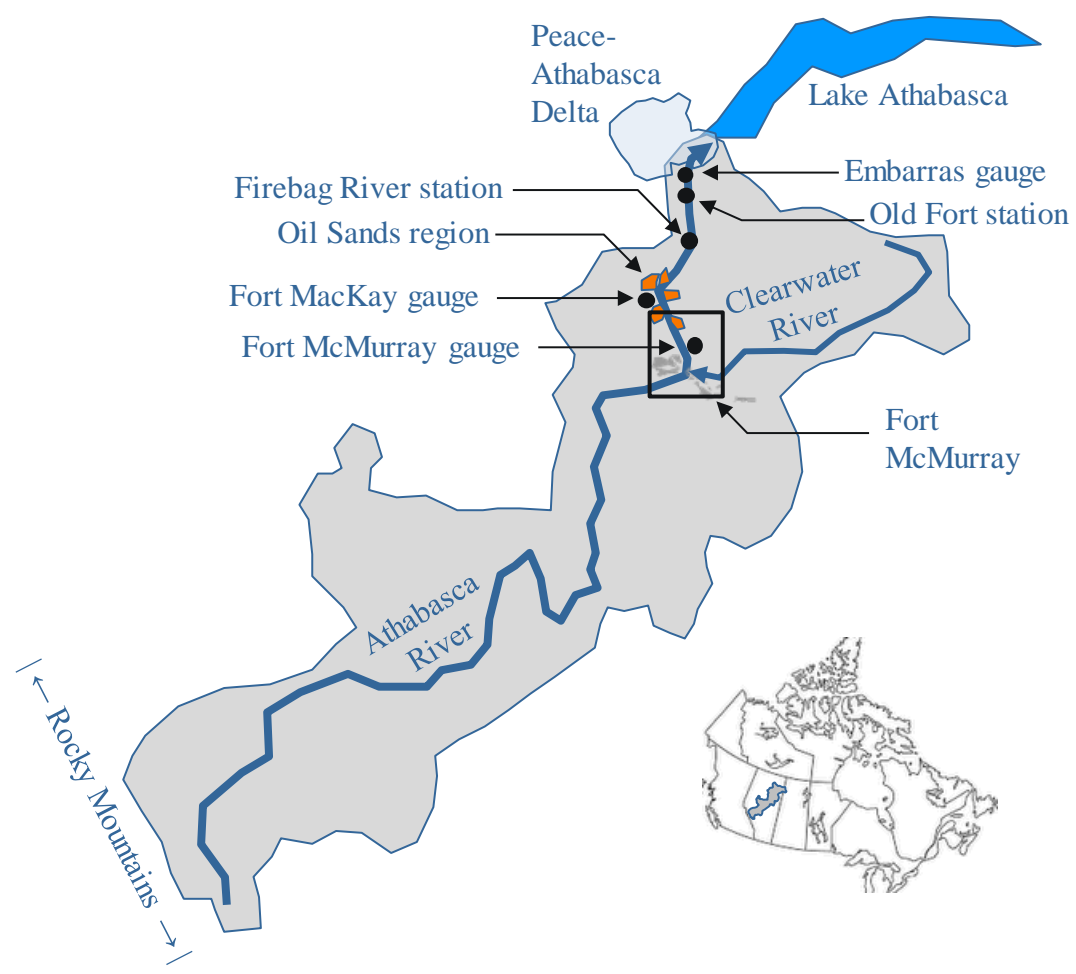

Figure 1. Athabasca River basin. Inset corresponds to the realm shown in Figure 2.

The oil sand region covers a large area of Northern Alberta and has one of the richest deposits of petroleum in the world. For a $65 \mathrm{~km}$ stretch of the lower Athabasca River, between Fort McMurray and downstream of Fort MacKay (see Figure 1), the river flows 
through the active oil sand surface mines. Much of the oil is extracted through open-pit mining and processed using water from the Athabasca River. Almost $5 \%$ of the river's average flow has been allocated for anthropogenic usage. Although approximately half of that amount is allocated for surface and in situ mining activities, less than $1 \%$ is used [13].

The lower Athabasca River contains many islands, secondary channels, wetlands, and floodplain lakes. Many of these secondary channels freeze to the bottom or have low oxygen levels during winter [14]. Sediment deposition areas occur downstream of tributaries (confluence bars), in mid-channel bars, in secondary channels and in side lake and wetland areas along the river. During high flow events, substantial amounts of oil sands material can be transported from tributaries into the river to be deposited in these depositional areas. Over time, these areas of high oil sands material are mixed and diluted with water and sediment coming from upstream.

One particular side lake of interest in this study is Shipyard Lake, which is located near the Suncor oil facilities on the east side of the Athabasca River and is within our model domain (see Figure 2). The lake, shown in Figure 3, has a surface area of 21.3 ha and a maximum depth of $2.2 \mathrm{~m}$ [15]. It is essentially a large wetland area that is flooded by higher flows from the Athabasca River [15]. Numerous small creeks feed the lake and water from the Athabasca River flows into Shipyard Lake over a low levee between the watercourse and water body. Flow begins to overflow the levee at an Athabasca River flow of $2800 \mathrm{~m}^{3} / \mathrm{s}$ [16], which corresponds to a water surface elevation of $237.7 \mathrm{~m}$ a.s.l. just upstream of the lake [16]. This corresponds to a water level elevation of approximately $240.1 \mathrm{~m}$ a.s.l. at the Athabascsa River gauge downstream of Fort McMurray [17], the location of which is shown in Figure 2.

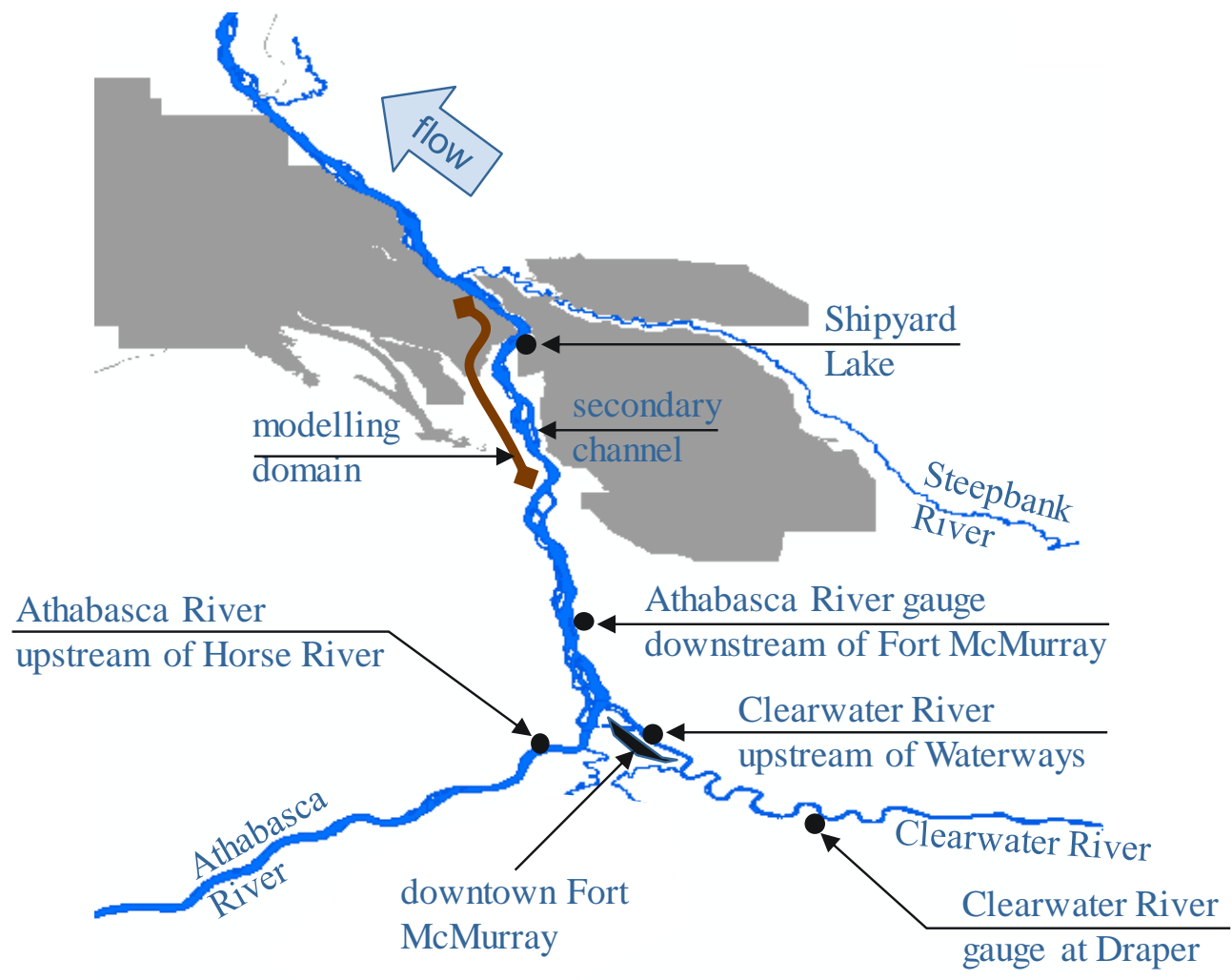

Figure 2. Study area with modelling domain. 

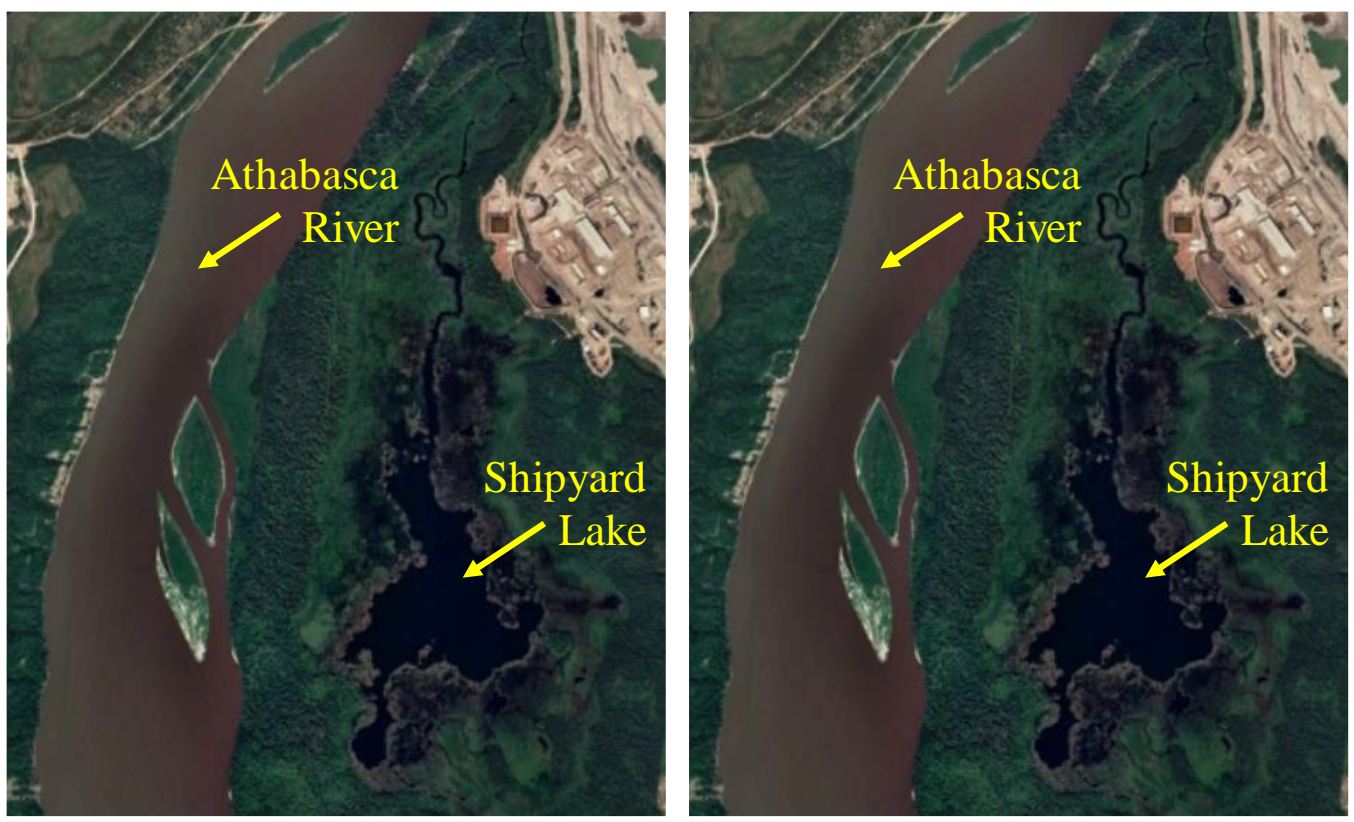

Figure 3. Shipyard Lake (left panel) and secondary channel (right panel). Both Google Earth maps are at the same scale.

A secondary channel is also included in the model domain, also shown in Figure 3. A cross-section of the Athabasca River main stem and the secondary channel is provided in Figure 4. Some water does flow into the secondary channel from the Athabasca River at a flow of $600 \mathrm{~m}^{3} / \mathrm{s}$.

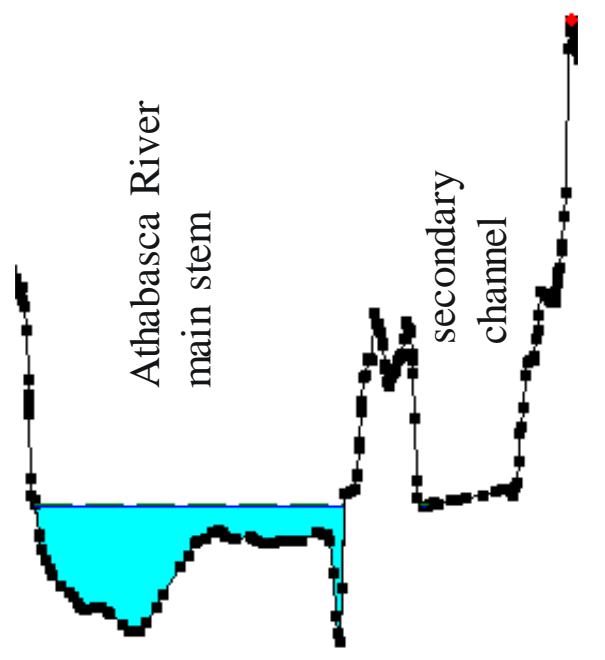

Figure 4. HEC-RAS cross-section of the Athabasca River main stem and secondary channel with water-level profile at a flow of $600 \mathrm{~m}^{3} / \mathrm{s}$.

A major tributary of the Athabasca River is the Clearwater River (see Figure 1 and Figure 2), which flows from the east into the Athabasca River at Fort McMurray. For an average flow of $600 \mathrm{~m}^{3} / \mathrm{s}$ at the gauge on the Athabasca River downstream of Fort McMurray (gauge 07DA001 - Athabasca River below Fort McMurray), the average annual flow from the Clearwater River recorded at the Draper gauge (gauge 07CD001 - Clearwater River at Draper) is $116 \mathrm{~m}^{3} / \mathrm{s}$ and ranges from 30 to $500 \mathrm{~m}^{3} / \mathrm{s}$ (see Figure 5). 


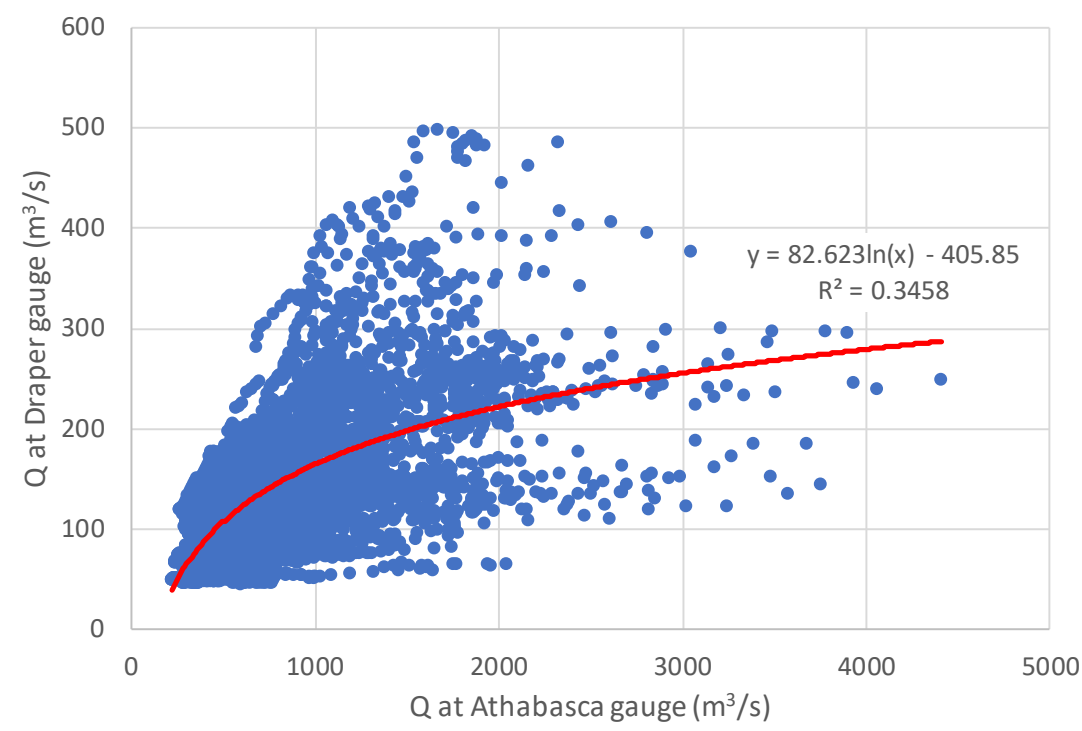

Figure 5. Flows recorded by the Athabasca River gauge below Fort McMurray (gauge 07DA001) and the Clearwater River gauge at Draper (gauge 07CD001). Flows are of daily means recorded on the same day over a 30-year period $(1990-2019))$.

Total suspended solids (TSS) data from four stations along the Athabasca River were used in the analysis:

- Athabasca River upstream of the Horse River - (Alberta Environment and Park's long term monitoring station AB07CC0030; Figure 2)

- Athabasca River upstream of the Firebag River confluence (Alberta Environment and Park's long term monitoring station AB07DA0980; Figure 1)

- Old Fort / Devil's Elbow (Alberta Environment and Park's long term monitoring station AB07DD0010 (open water) and AB07DD0105 (ice-cover); Figure 1)

- Clearwater River upstream of Waterways (Alberta Environment and Park's monitoring station AB07CD0200/210/090 Clearwater River upstream of Waterways; Figure 2)

Empirical relationships between TSS concentrations and river discharge are provided in the supplementary materials, from which equations were established and are shown in Figure 6 for a lower flow regime. Sediment transport was simulated only for the $2800 \mathrm{~m}^{3} / \mathrm{s}$ flow since, in this scenario, Athabasca River water flows into both the secondary channel and Shipyard Lake. A total flow of $2800 \mathrm{~m}^{3} / \mathrm{s}$ at the Athabasca River gauge below Fort McMurray corresponds to a flow of $250 \mathrm{~m}^{3} / \mathrm{s}$ for the Clearwater River (from Figure 5), yielding, through simple subtraction, a flow of $2550 \mathrm{~m}^{3} / \mathrm{s}$ at the Athabasca River station upstream of Fort McMurray. From Figure 6, the TSS concentrations are respectively 575.5 and $86.8 \mathrm{mg} / \mathrm{l}$ for the upper Athabasca and Clearwater rivers.

\section{Hydraulic modelling setup}

Water level gauges are not present within the $15 \mathrm{~km}$ modelling domain. There is an active gauge (records from 1957 to present) at the Water Survey of Canada (WSC) station approximately $13 \mathrm{~km}$ upstream of the modelling domain at Fort McMurray (gauge 07DA001 - Athabasca River below Fort McMurray) and a discontinued gauge (recordings only from 1959 to 1966) approximately $16 \mathrm{~km}$ downstream of the modelling domain at Fort MacKay (gauge 07DA003 - Athabasca River near Fort MacKay). The average flow at the gauge at Fort McMurray is about $600 \mathrm{~m}^{3} / \mathrm{s}$. This flow was used to calibrate the WASP simulations of tracer mixing from a hypothetical outfall from the right bank at the upstream boundary of the model domain. A flow of $2800 \mathrm{~m}^{3} / \mathrm{s}$ was used for validation and to simulate flow from the Athabasca River into Shipyard Lake. 


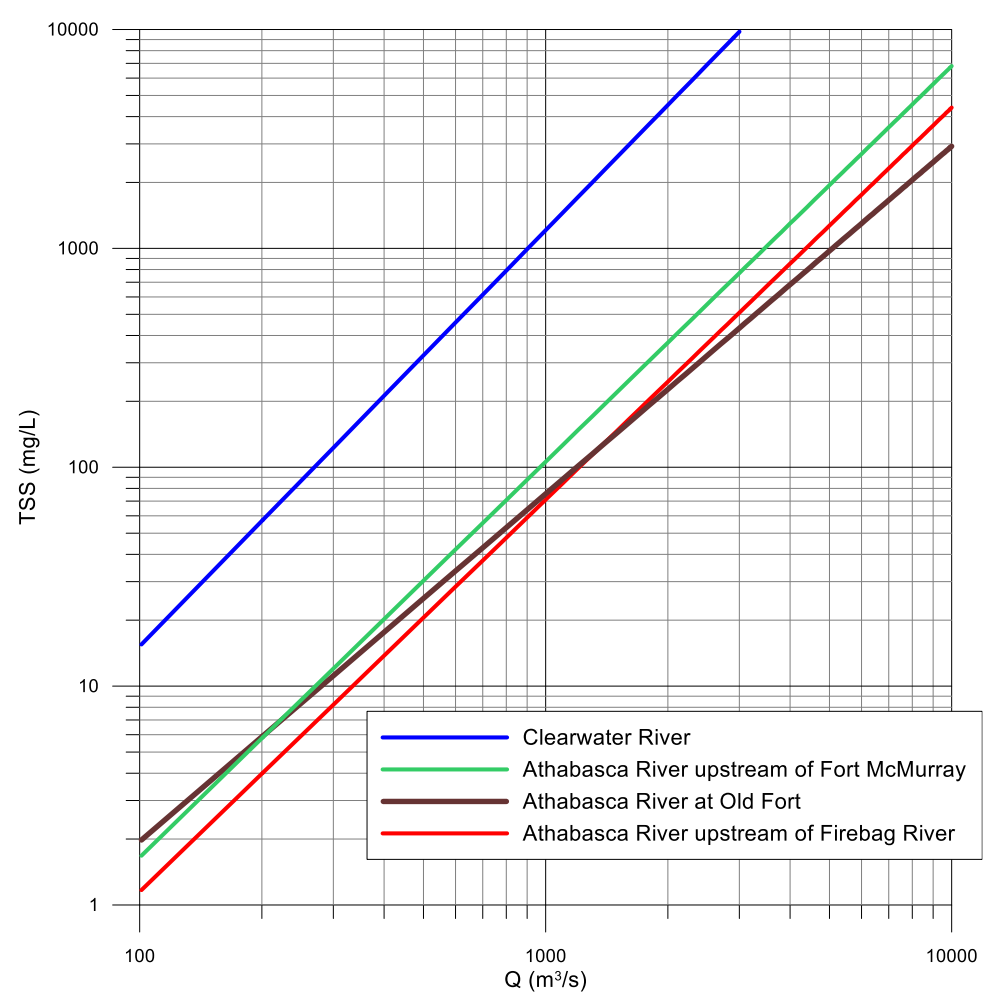

Figure 6. Discharge vs. total suspended sediment concentrations.

The hydraulic model HEC-RAS [18], developed by the U.S Army Corps of Engineers, was used to generate the segmentation for the WASP water quality model. The water level elevations of the HEC-RAS model at flows 600 and $2800 \mathrm{~m}^{3} / \mathrm{s}$, which formed the geometrical basis for the WASP segmentation, were verified with flow simulations using the hydraulic model ONE-D, a hydrodynamic model that uses a finite difference implicit scheme for the solution ([19-20] both referenced in [21]). Both mass and momentum of sub-critical fluid motion are conserved for open-channel flow. The model is robust and well tested with many consultancy applications (e.g. [22-23]). Bathymetry data were obtained from Alberta Environment and Parks (AEP) [24].

Figure 7 shows how the water level profiles modelled in ONE-D match with the water level elevations recorded at the gauges at Fort McMurray and Fort MacKay for an average flow of $600 \mathrm{~m}^{3} / \mathrm{s}$ and a higher flow of $2800 \mathrm{~m}^{3} / \mathrm{s}$. The water level elevations modelled with HEC-RAS for the same steady-state flow coincide well with the ONE-D water level profile.

\section{Water-quality modelling setup}

The Water Quality Analysis Simulation Program (WASP 8.32) was used to model the water quality of the river-lake system. WASP is a general dynamic model that applies a segmentation network to solve the conservation of momentum, energy, and mass equations and simulate contaminant and sediment transport. WASP was initially developed in the 1980s and has undergone many upgrades since then. WASP is a widely used model, especially in North America, for addressing various environmental and water quality concerns. The WASP segmentation can be structured in 1D for streams, or 2D for rivers with branching channels or 3D for lakes.

The WASP stream transport module, TOXI, is able to calculate the flow of water, sediment and dissolved constituents through branched and ponded segments and is coupled with flow routing for free flow streams, ponded segments, and backwater reaches. The kinematic wave was used for the 1D flow routing, which is based on solutions of onedimensional continuity equations and a simplified form of the momentum equation that considers effects of gravity and friction, and calculates variations in velocities, widths and 
depths throughout the network. Flow through the ponded segments is calculated based on a sharp-crested weir equation, which calculates outflow based on water elevation above the weir crest, using kinematic wave flow for a river and ponded weir overflow for a lake. For the current study, boundary and initial conditions were defined based on water quality data of the closest station to the study area by spatial linear interpolation.
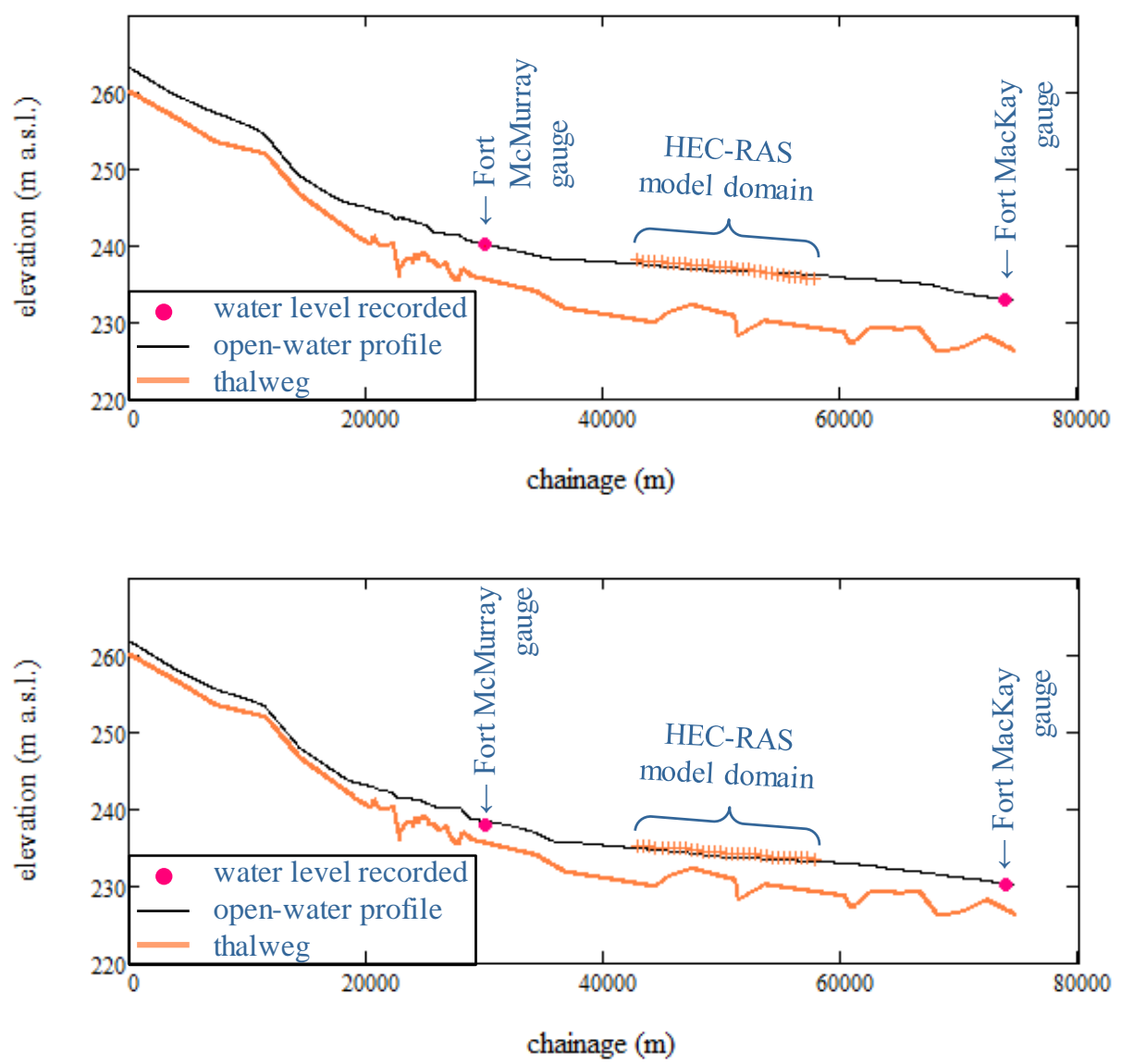

Figure 7. Verification of water surface elevations of the HEC-RAS model with ONE-D for flows of $600 \mathrm{~m}^{3} / \mathrm{s}$ (top panel) and $2800 \mathrm{~m}^{3} / \mathrm{s}$ (bottom panel).

Input data for the model includes channel geometry, flow routing, boundary conditions, environmental time functions, loads and initial conditions for segments. Geometry for the WASP segments (average depths, widths and slopes) was extracted from the fiftyeight HEC-RAS cross-sections, which were spaced at a distance of $493 \mathrm{~m}$ apart. Segments are a series of discretized components used to estimate the model state variables at every time step. A depth exponent of 0.3 was used to characterize the irregular shape of the channel. The sediment transport model is an independent set of routines with associated parameters for the model.

The domain was modelled with a network of river segments, a secondary channel and a side lake. Water quality modelling of such a complex system requires special consideration of the varying hydrodynamics within the system. The primary segments of the system are $493 \mathrm{~m}$ long; as mentioned before, right stream segments accommodate $20 \%$ of the width of cross-sections produced by HEC-RAS for the $600 \mathrm{~m}^{3} / \mathrm{s}$ scenario and $10 \%$ of the width for the $2800 \mathrm{~m}^{3} / \mathrm{s}$ flow scenario.

Bathymetric information for Shipyard Lake was obtained from a bathymetry survey carried out by Golder [15]. The lake was divided into two segments:

- a deep part with a surface area of 14 ha and an average depth of $1.5 \mathrm{~m}$ and

- a shallow part with a surface area of 7.3 ha and an average depth of $0.75 \mathrm{~m}$. 
As mentioned above, the mixing length for the stream is long, and the geographical complexity of the study area cannot be represented with a 1D modelling approach alone. On the other hand, a 2D approach would require higher data computational resources for such a long stream. Quasi-2D models can be a reasonable alternative by using the simplicity of a 1D solution but still capturing 2D discretisation of the substance transport.

The stretches between every two cross-sections of the HEC-RAS model were divided into two stream tubes. The flow from the Clearwater River controlled the segment on the right side (right stream), and the main Athabasca River system controlled the segments on the left side (left stream), as shown in Figure 8. Flow for the secondary channel was supplied through the right side stream. It was estimated that $2 \%$ of flow into Shipyard Lake was required to maintain water volume continuity. The flow through Shipyard Lake was anticipated to flow back into the right side stream just downstream of the lake. A schematic of the segmentation is shown in Figure 9.

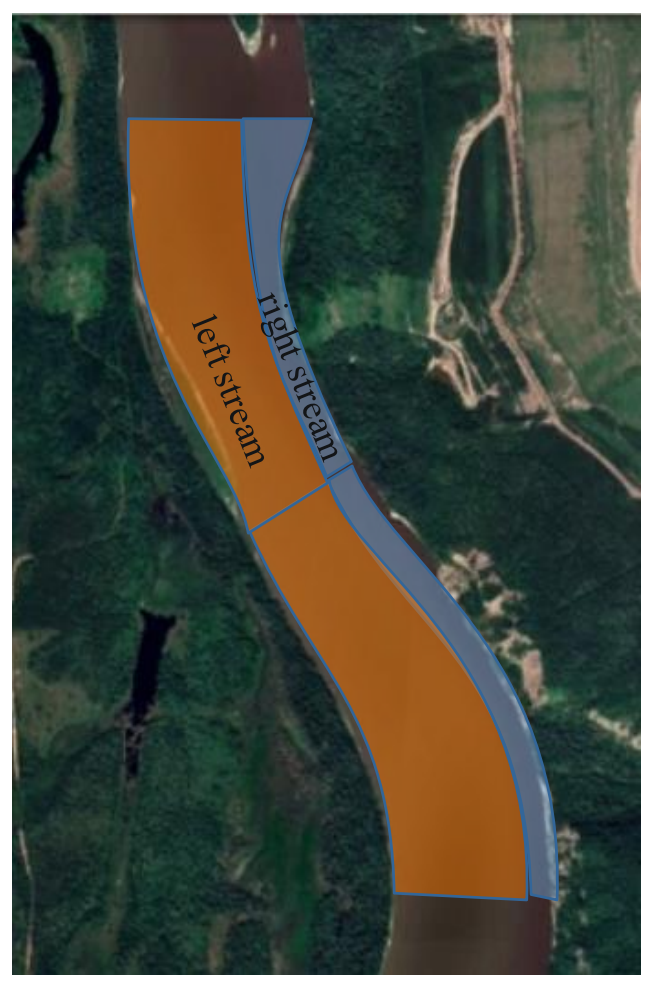

Figure 8. Discretising left and right stream along the Athabasca River modelling domain (map source: Google Earth).

In order to characterize erosion and sedimentation, benthic segments were added under each surface water segment. The user can now separate solids into clay, silt and sand, which can refine simulation results of solids. The user has four choices for simulating solids in WASP: solid flow fields, descriptive, the mechanistic Van Rijn equation, and the mechanistic Robert equation. Currently, WASP has two kinetic modules for modelling sediment transport. For the current study, the advanced toxicant module was used because it is considered to be the best module to simulate oil-sands associated substances.

\section{WASP mixing calibration $\left(Q=600 \mathrm{~m}^{3} / \mathrm{s}\right.$}

Calibration of the mixing of the WASP model was done using simulation results from the Athabasca River Model (ARM) [14-15]. ARM is a vertically averaged, two-dimensional mixing model used to predict substance concentrations varying across the width and length of the lower Athabasca River for various flow conditions. Mid-field mixing is represented by dispersion equations described by Fischer et al. [25]. The same representation is used for passive ambient mixing in the Cornel Mixing Zone Expert System (CORMIX) [26] except that, for ARM, transverse mixing coefficients have been calibrated based on a 
tracer-dye study completed in 2003 [27-28] and validated using a range of data sources [29]. The calibration of ARM is described in [27] and [28].
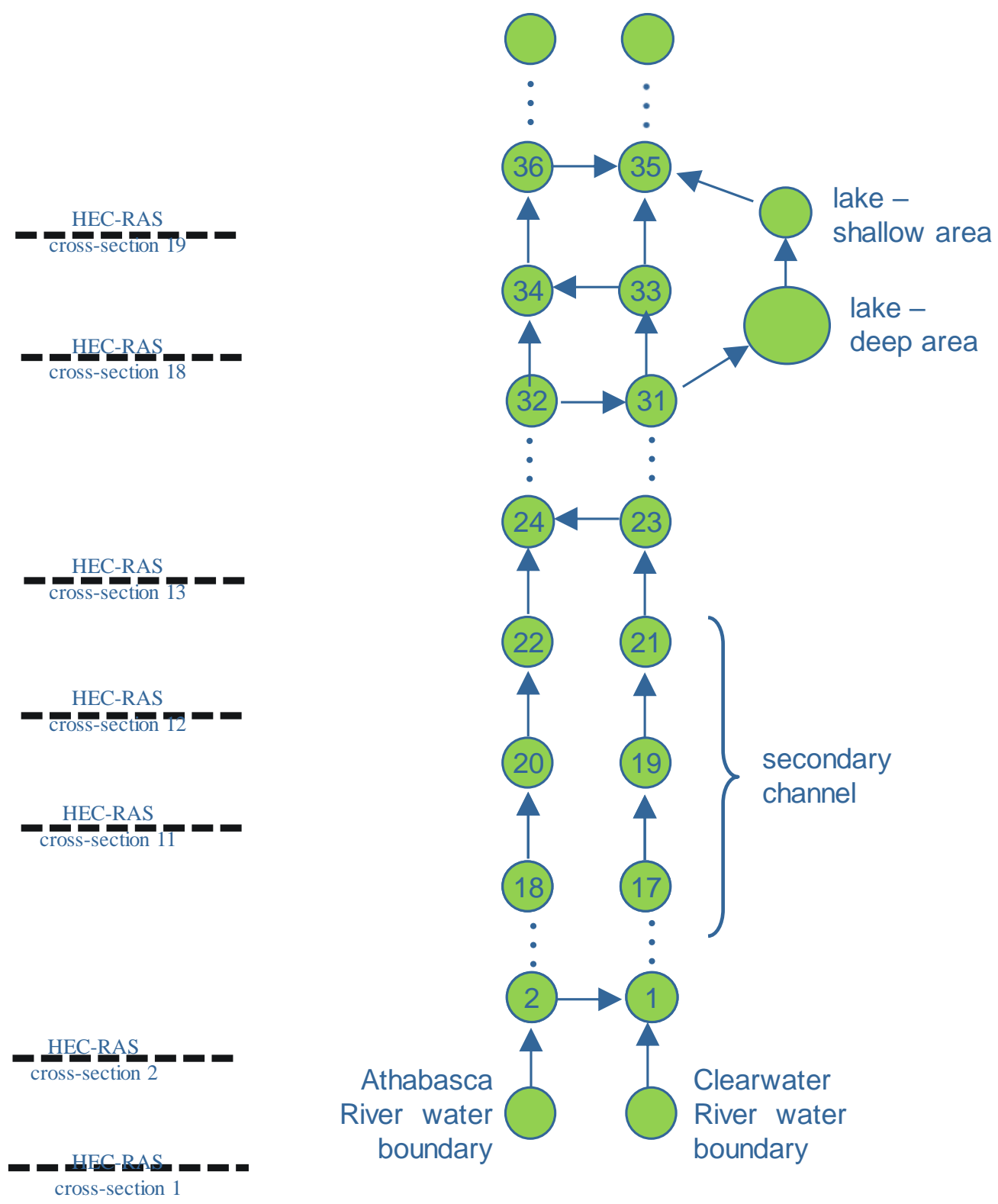

Figure 9. Segmentation of the model domain. left panel: HEC-RAS cross sections; right panel: WASP surface segments.

A hypothetical conservative tracer was chosen to calibrate the mixing path of the WASP model to the ARM predictions. A load of $5670 \mathrm{~kg} /$ day, which led to the chemical concentration of $1 \mathrm{mg} / \mathrm{l}$ in the most-upstream segment (Segment 1 ) was added. The flow system included two upstream boundary conditions: the Athabasca River water for the left stream boundary and the Clearwater River water for the right stream boundary.

As expected, the conservative tracer was transported to the left stream when a flow was designated between them. Segments divided by islands (segment combinations 1617, 18-19 and 20-21) had no flow between them. WASP simulated the concentrations of the tracer in each segment. These values were compared with values predicted by the ARM model and shown in Figure 10. 


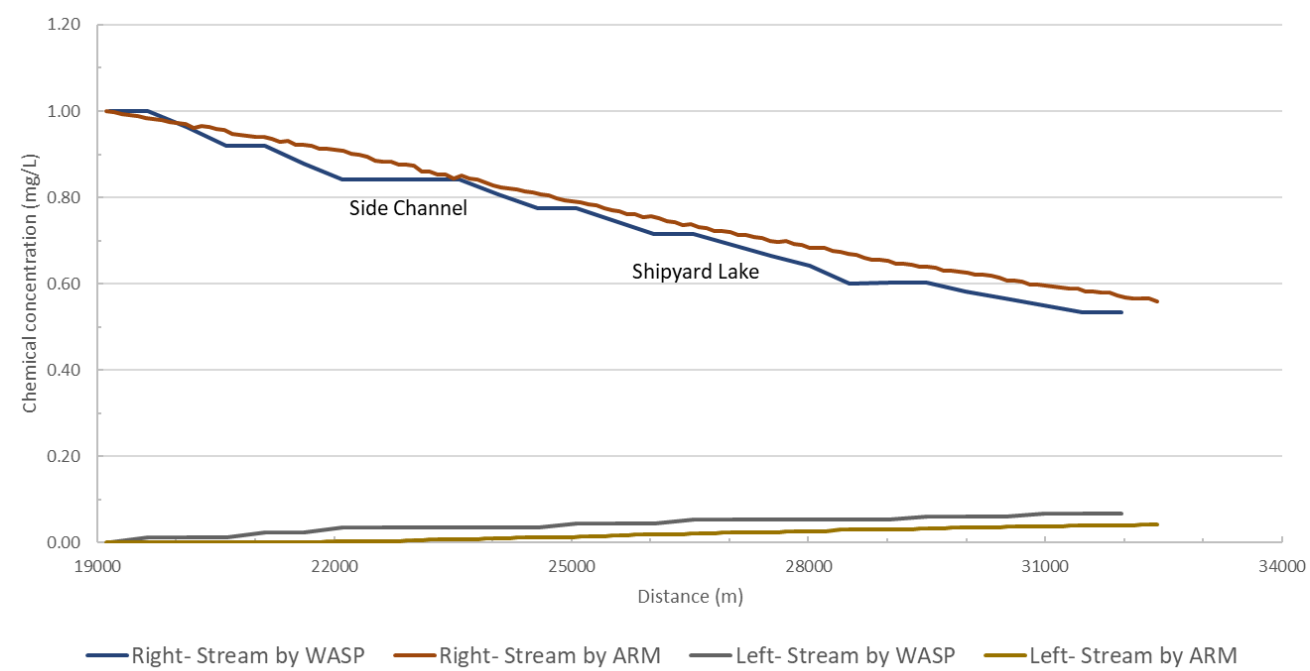

Figure 10. Calibration of WASP with ARM data of the mixing between the left and right streams of the Athabasca River at a flow of $600 \mathrm{~m}^{3} / \mathrm{s}$.

Good agreement for both left and right streams was observed. As can be seen, both models predicted the same trend for both streams: a reduction in chemical concentrations in the right stream and an increase in chemical concentrations in the left stream. Contour plots of the tracer concentrations modelled in WASP and ARM are shown in Figure 11.
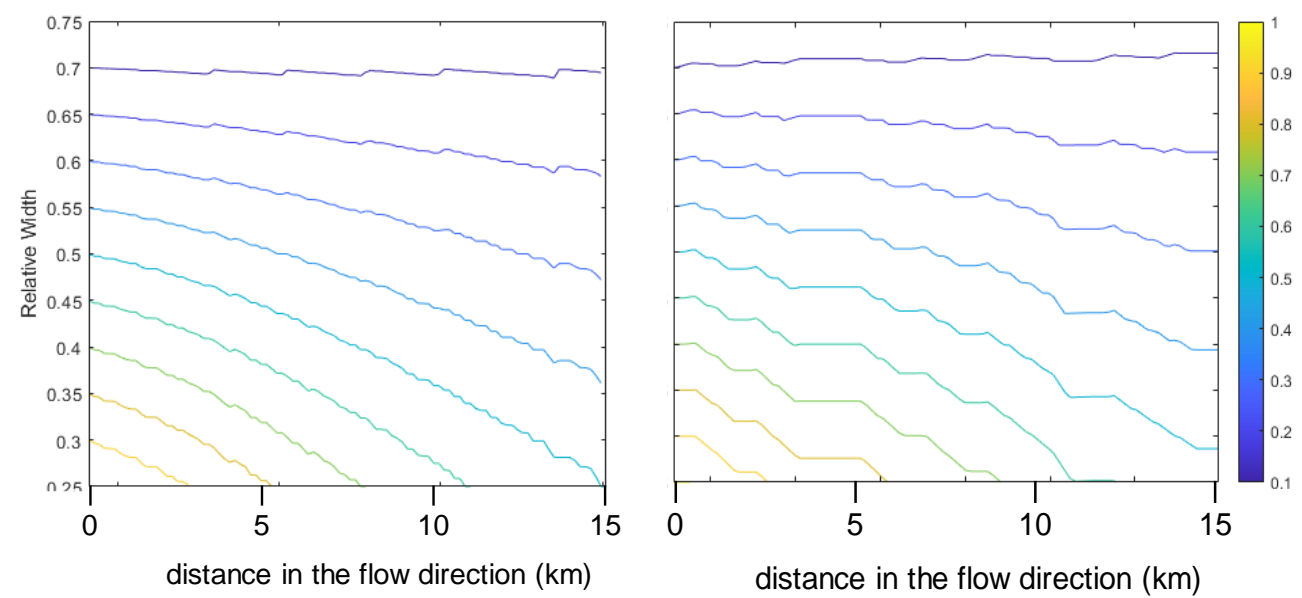

Figure 11. Contour maps for tracer concentration based on the ARM model (left panel) and WASP model (right panel) for the $600 \mathrm{~m}^{3} / \mathrm{s}$ flow scenario.

\section{WASP mixing validation $\left(Q=2800 \mathrm{~m}^{3} / \mathrm{s}\right)$}

A simulation with a higher flow of $2800 \mathrm{~m}^{3} / \mathrm{s}$ was carried out for which both Shipyard Lake and the secondary channel become flooded. The results of the two models for the two streams are shown in Figure 12. Again, mixing is evident since the tracer concentrations are increasing in the right stream and decreasing in the left stream, both in the flow direction. Mixing is more rapid for the $2800 \mathrm{~m}^{3} / \mathrm{s}$ scenario since the tracer concentrations drop to $40 \%$ of the original concentration at the end of the $15 \mathrm{~km}$ stretch, whereas the concentrations only drop to $55 \%$ in the $600 \mathrm{~m}^{3} / \mathrm{s}$ scenario (Figure 10). Contours of the tracer concentrations simulated in ARM and WASP are provided for the $2800 \mathrm{~m}^{3} / \mathrm{s}$ flow case in Figure 13. 


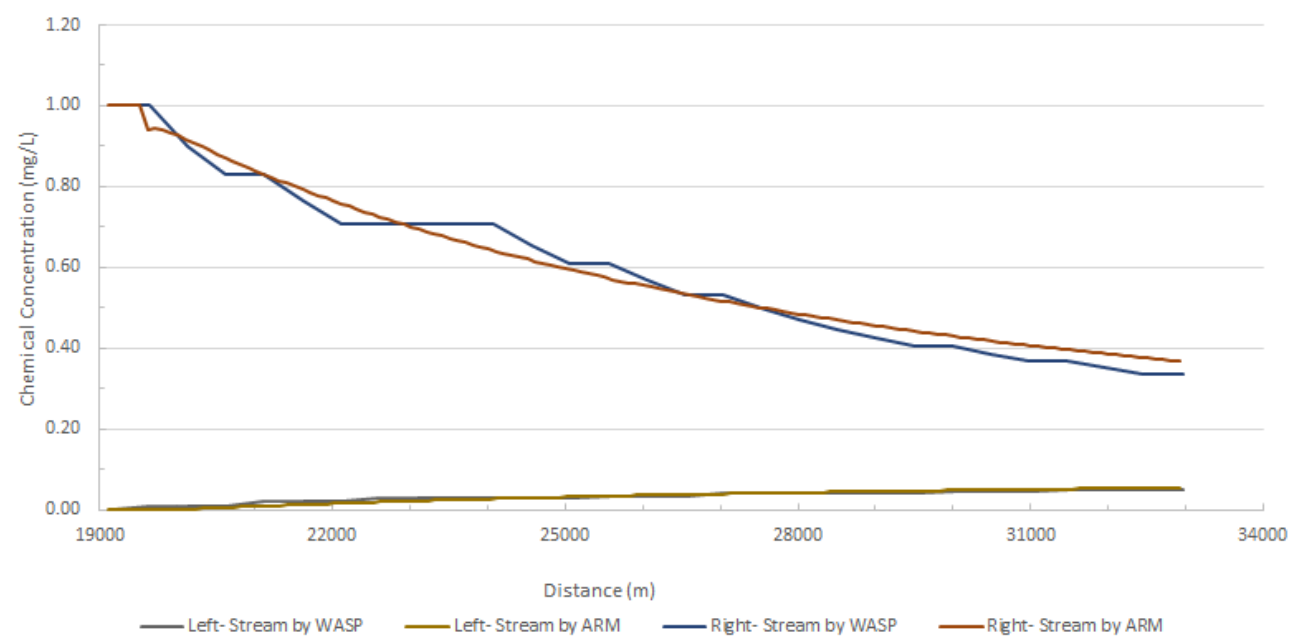

Figure 12. Validation of WASP with ARM of the mixing between the left and right streams of the Athabasca River at a flow of $2800 \mathrm{~m}^{3} / \mathrm{s}$.
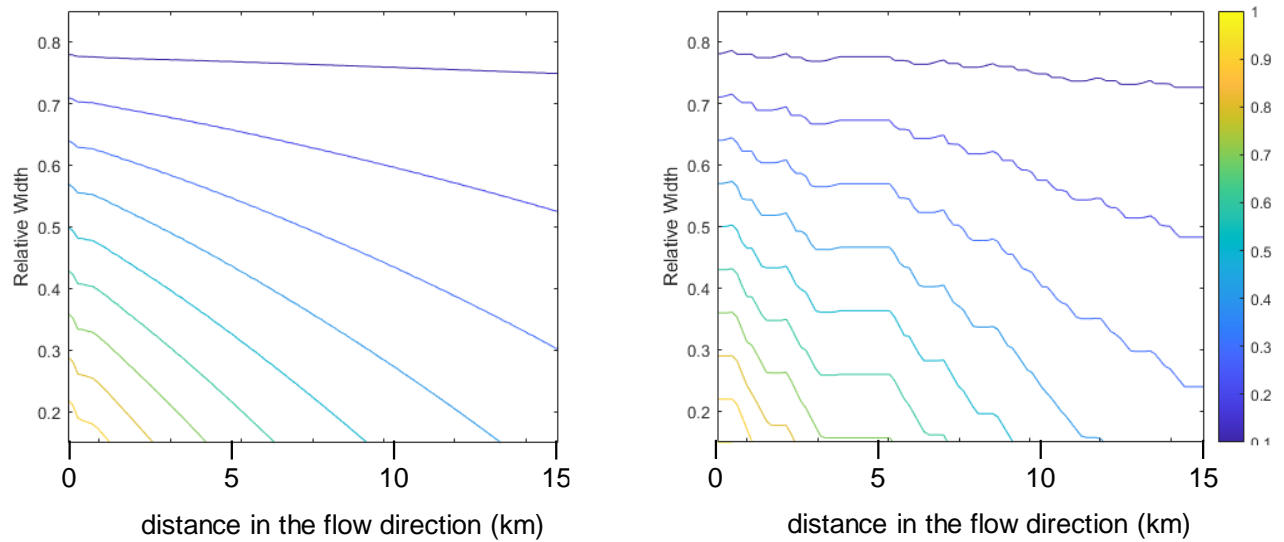

Figure 13. Contour maps for tracer concentration based on the ARM model (left panel) and WASP model (right panel) for $2800 \mathrm{~m}^{3} / \mathrm{s}$ flow scenario.

\section{Sediment transport modelling}

Suspended solids and benthic sediments are key components of the water quality of rivers and lakes. When the flow velocity decreases, as is the case when, for example, a river flows into a lake or reservoir, suspended sediments will settle out. Key constituents in oil sands process water, such as selenium and polycyclic aromatic hydrocarbons, tend to sorb to fine sediments. For the current study, separate size classes were represented using the descriptive solids transport option in WASP. For the descriptive solids transport, constant settling and resuspension velocities were defined for each segment. Settling velocity of silt and clay were calculated from Stokes Law, and the settling velocity of sand was estimated based on the equation from Ferguson and Church [30].

Size classes for suspended solids were estimated based on suspended sediment samples collected from the Lower Athabasca River using continuous flow centrifugation in 2012 and 2013 as part of the Joint Oil Sands Monitoring Program [1].

Measured TSS data were fitted versus the flow rate for the sediment sampling stations. Power functions were used to fit the data yielding acceptable $r^{2}$ values $\left(r^{2}>0.6\right)$ for all correlations. This provided equations to estimate TSS based on the given flow rates. For the sediment transport simulation, we used the flow scenario of $2800 \mathrm{~m}^{3} / \mathrm{s}$ because at that flow, both the secondary channel and Shipyard Lake are flooded by Athabasca River water. A flow of $2800 \mathrm{~m}^{3} / \mathrm{s}$ corresponds to a flow of $250 \mathrm{~m}^{3} / \mathrm{s}$ for the Clearwater River (from 
Figure 5), and a flow of $2550 \mathrm{~m}^{3} / \mathrm{s}$ along the upper Athabasca River reach, which represents a flow ratio of approximately $10 \%-90 \%$, respectively. Although the model domain is situated downstream of the Athabasca/Clearwater river confluence, for the purpose for of showing proof-of-concept in this study, the 10/90 percentage ratio was maintained for the right/left streams.

After obtaining TSS values for the flow scenario for the water quality stations, an interpolation was done to obtain initial sediment concentrations for each segment along the study area (see Figure 14). For segments on the right stream (segments with odd numbers), linear interpolation between Clearwater River at Draper and Athabasca/Firebag confluence was carried out. For left stream segments (segments with even numbers), values were interpolated between the station upstream of the Athabasca/Clearwater confluence and Athabasca/Firebag confluence. After obtaining TSS amounts for each segment, the average ratio of long-term means was used to estimate the concentration of silt, clay and sand in each segment. Initial concentrations for benthic segments were estimated from available bed sediment data for the Lower Athabasca River collected as part of the Regional Aquatics Monitoring Program [31].

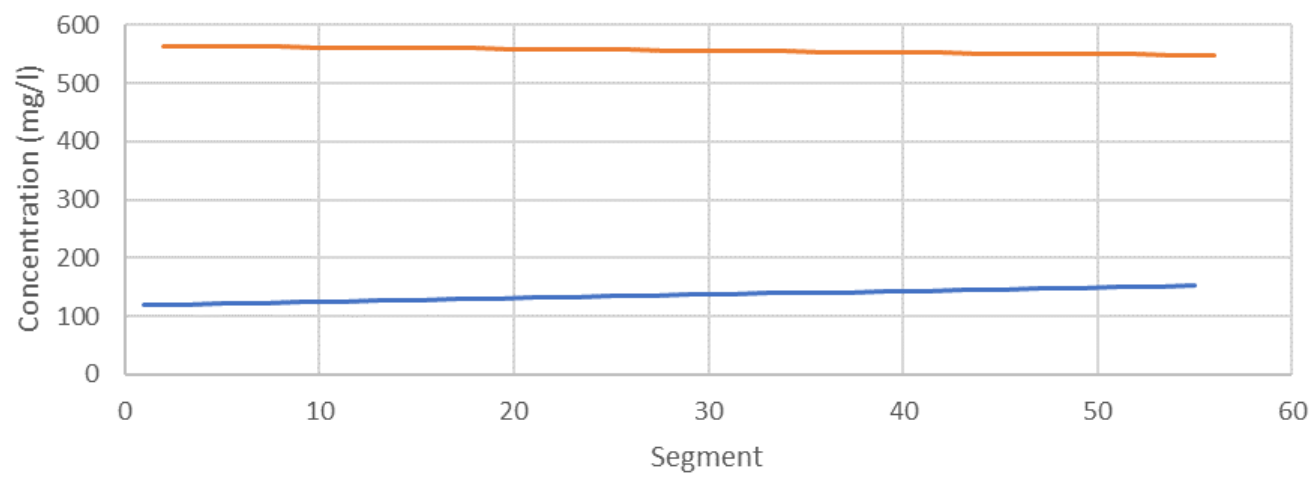

Left- Stream $\quad$ Right-Stream

Figure 14. Initial TSS concentration along modelling domain; flow is from left to right.

From Figure 6, at flows greater than approximately $1500 \mathrm{~m}^{3} / \mathrm{s}$, TSS concentrations tend to decrease from the Athabasca River station at Fort McMurray to the Firebag and Old Fort stations, due to mixing with the Clearwater River, which has relatively clear water relative to the Athabasca River mainstem. Within the reach, sediment deposition may increase during higher flows due to flooding of secondary channels and floodplain lakes as the flows increase.

The model was run until it reached an equilibrium state, after which no significant changes in the sediment concentrations in the surface water segments were observed. It was assumed that an equilibrium state has been reached when there was no significant change in sediment concentration in the water body for more than a simulation time of 24 hours. For the current study, clay, silt and sand were modelled, and the results of these for both the left and right streams of the Athabasca River are shown in Figure 15.

The mechanics of solid transport in WASP is based on advection, and suspended sediments are only transported transversely when there is a flow routed between segments of the right and left streams. It is evident that the left stream segments have higher sediment concentrations than the right stream segments. Also, sediment concentrations tend to drop in the left stream and increase in the right stream, both with flow direction, which is attributed to the transverse mixing, as is the case for the tracer simulations.

For all segments, including left and right streams, it was observed that, for the water columns, the amount of sediments decreases in order from silt, to clay and then sand. Due to the higher settling velocity for sand, it can be expected that there would be more sand deposits in the river compared to silt and clay. Sand is typically transported as a bedload 
or during higher velocity flows due to its roughness and higher density [32-34]. Due to its low settling velocity, clay is the dominant sediment texture in the water column.
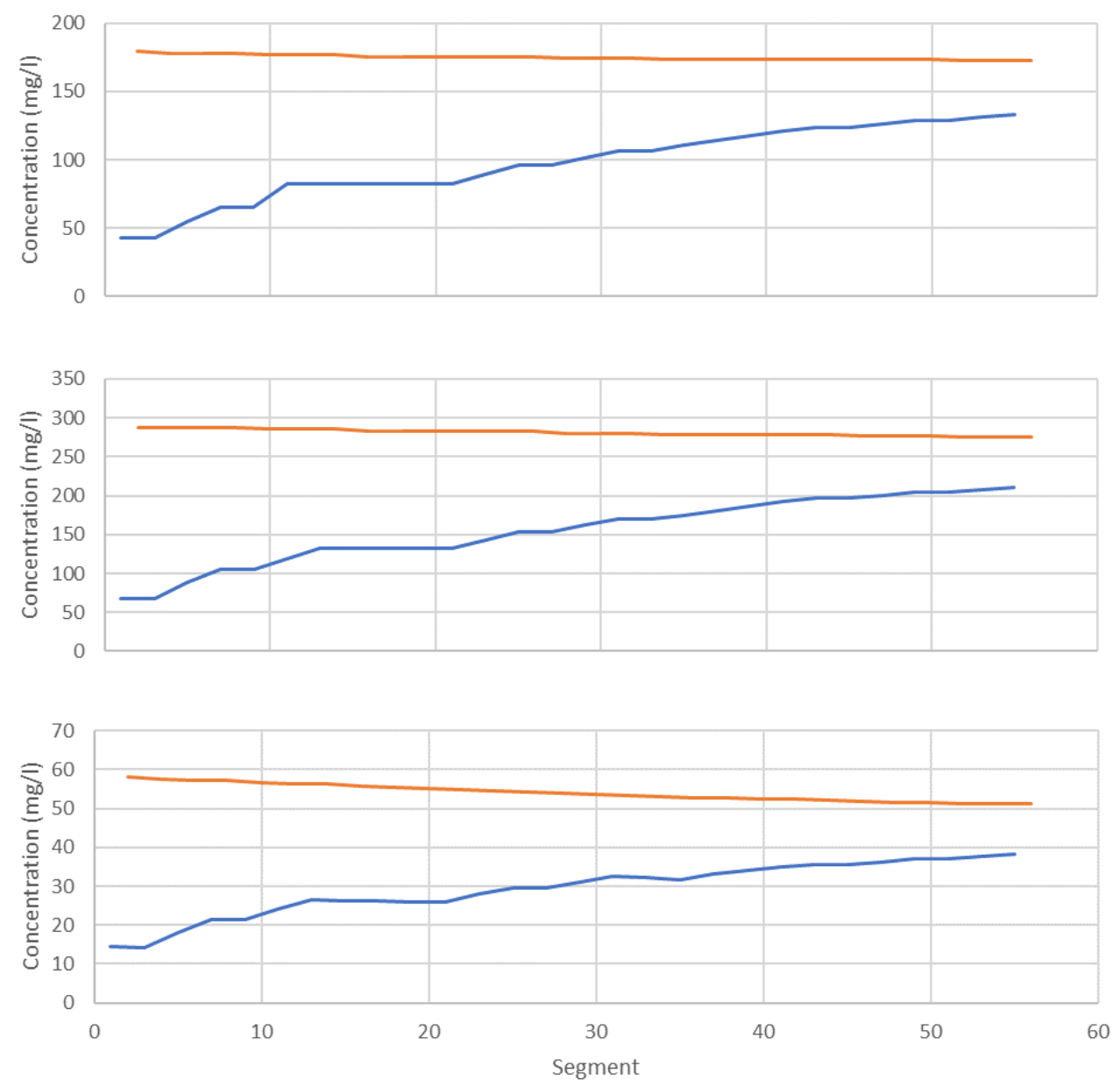

Figure 15. Simulated concentrations of clay (top panel), silt (middle panel) and sand (bottom panel).

At Shipyard Lake, a considerable deposition of sediment in the lake was simulated compared to the sediment in the right stream of the Athabasca River (see Figure 16). The flow through the lake is in the direction of: right stream $\rightarrow$ deep part $\rightarrow$ shallow part $\rightarrow$ right stream (further downstream). The higher sedimentation in the lake is due to the drop in flow velocity of the water entering the lake. Much of the sediment of all three textures is deposited in the deeper part of the lake with some additional deposition in the shallow lake area. The amount of solids increases in the surface benthic segments because settling dominates over resuspension in the lake.

\section{Summary and Conclusions}

A novel methodology was proposed to simulate transverse mixing along a long stream of a river network with a secondary channel and side lake. A steady-state water quality model based on two flow scenarios (600 and $2800 \mathrm{~m}^{3} / \mathrm{s}$ ) was developed to study transverse mixing and sediment deposition in the modelling domain. 


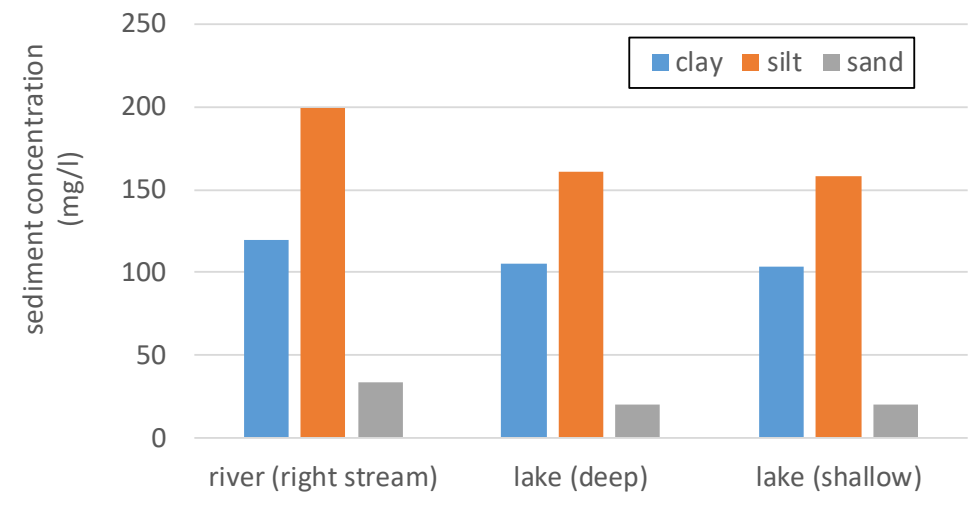

Figure 16. Water-column concentrations of clay, silt and sand in the right stream of the river and the deep and shallow portions of Shipyard Lake.

The first objective of this study was to model transverse mixing in the river-lake system. Good agreement with the previously developed ARM model was observed. It was established that a quasi-2D approach is a reasonable and accurate means of modelling transverse mixing of the system with a minimal processing time compared to more complex 2D models. The approach is also well suited for scaling up to a larger river network in future work by extending the modelling domain from Fort McMurray to the Athabasca Delta.

The second objective was to quantify deposition of sediments along the system. As expected, much of the sediment load deposits are found within the secondary channel and the side lake, with less deposition in the main channel. It was observed that coarser materials tend to deposit in the deep part of the lake, where the Athabasca River water first enters the lake. Due to the longer settling time for finer sediments, they were the main sediments suspended in the main stem.

The last objective was to emphasize the importance of drawing on the output from additional models to complement the water-quality modelling exercise. To support the water-quality modelling with WASP, the hydrodynamics of the water-quality modelling domain was analyzed using HEC-RAS and ONE-D. The ONE-D model has an extended domain that incorporates recordings from gauge stations. The calibrated and validated ARM model was also useful to calibrate the transverse mixing within the WASP model. Should we scale up to extend the modelling stretch from Fort McMurray to the Athabasca Delta, additional models, in particular a hydrological model of the Athabasca River basin, should also be included. This will be essential to predict the state of the river's water quality under a changing climate scenario in the future. The impacts of an ice cover on the river's water quality should also be considered in future research.

Author Contributions: Conceptualization, T.R. and K-E.L.; methodology, K-E.L.; model setup, E.A. and P.S.; calibration, P.S. and K-E.L., validation, P.S.; formal analysis, P.S. and K-E.L.; investigation, P.S., T.R. and K-E.L.; resources, T.R. and K-E.L.; data curation, T.R. and K-E.L.; writing-original draft preparation, P.S. and K-E.L.; writing-review and editing, T.R. and K-E.L.; supervision, T.R. and K-E.L.; project administration, T.R. and K-E.L.; funding acquisition, T.R. and K-E.L. All authors have read and agreed to the published version of the manuscript.

Funding: This research was funded by Alberta Environment and Parks and the Integrated Modelling Program for Canada (IMPC) under the University of Saskatchewan's Global Water Futures (GWF) program.

Conflicts of Interest: The authors declare no conflict of interest. The funders had no role in the design of the study; in the collection, analyses, or interpretation of data; in the writing of the manuscript, or in the decision to publish the results. 


\section{Appendix A}

Figure A1 to A4 provide a wider range of total suspended sediment (TSS) vs. flow (Q) for Athabasca River upstream of Fort McMurray (Figure A1), Clearwater River (Figure A2), Athabasca River upstream of Firebag River (Figure A3 and Athabasca River at Old Fort (Figure A4)

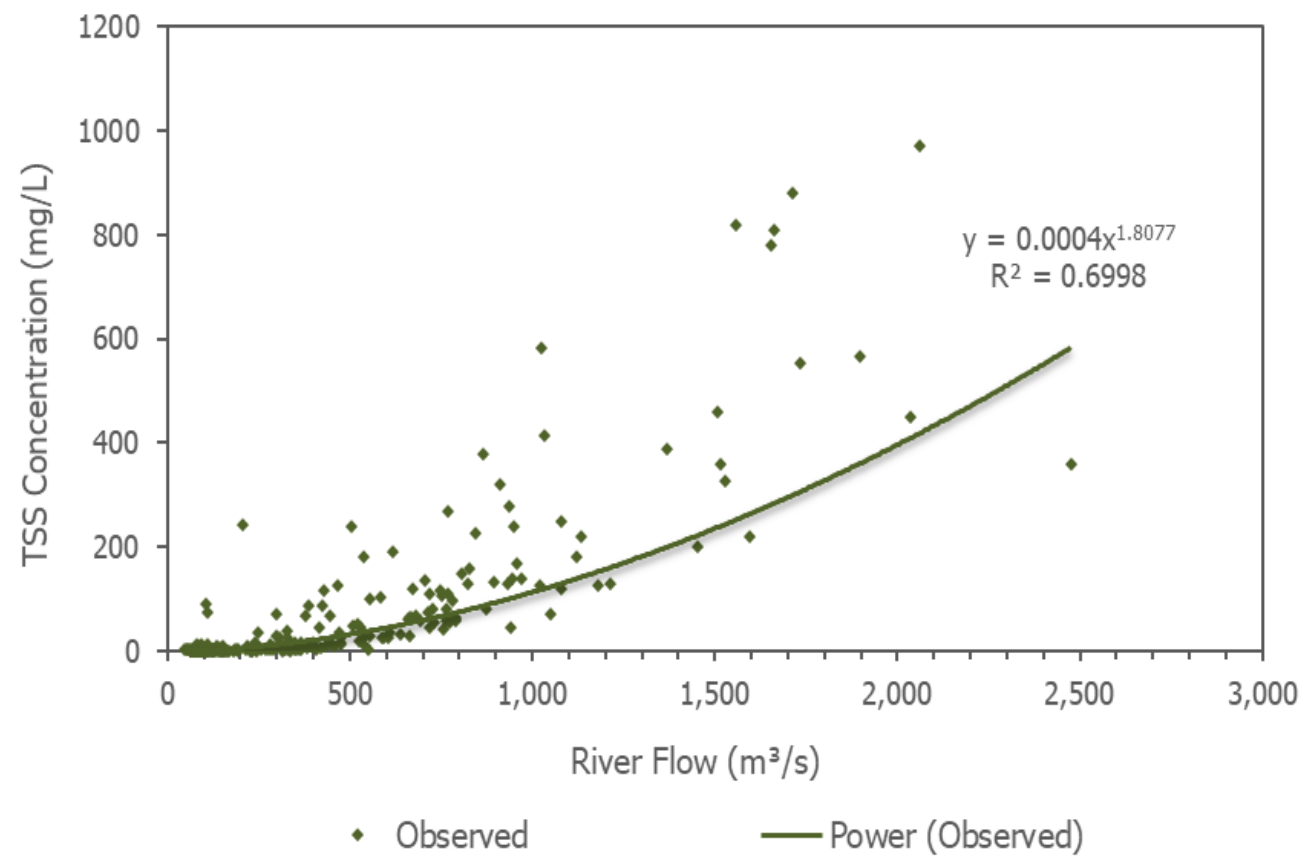

Figure A1. Total suspended sediment vs. flow for Athabasca River upstream of Fort McMurray.

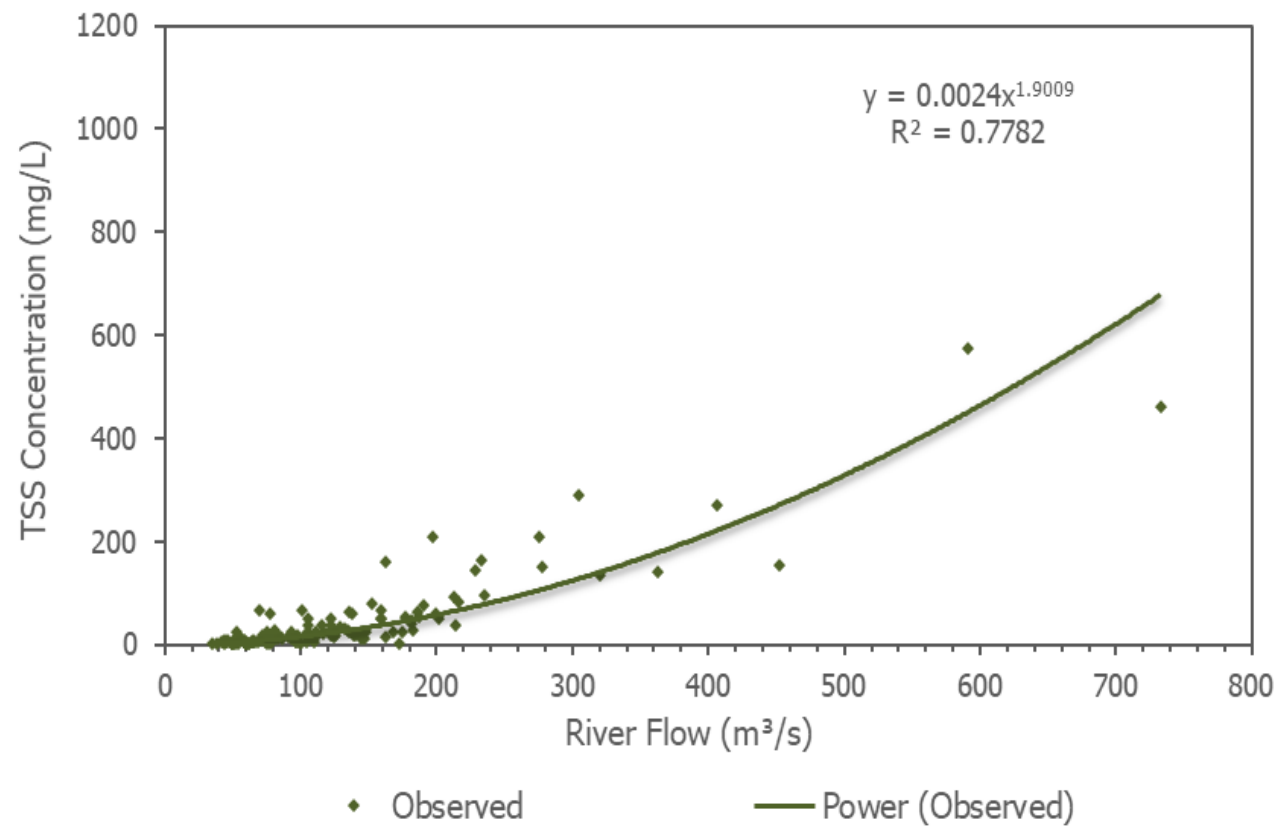

Figure A2. Total suspended sediment vs. flow for Clearwater River. 


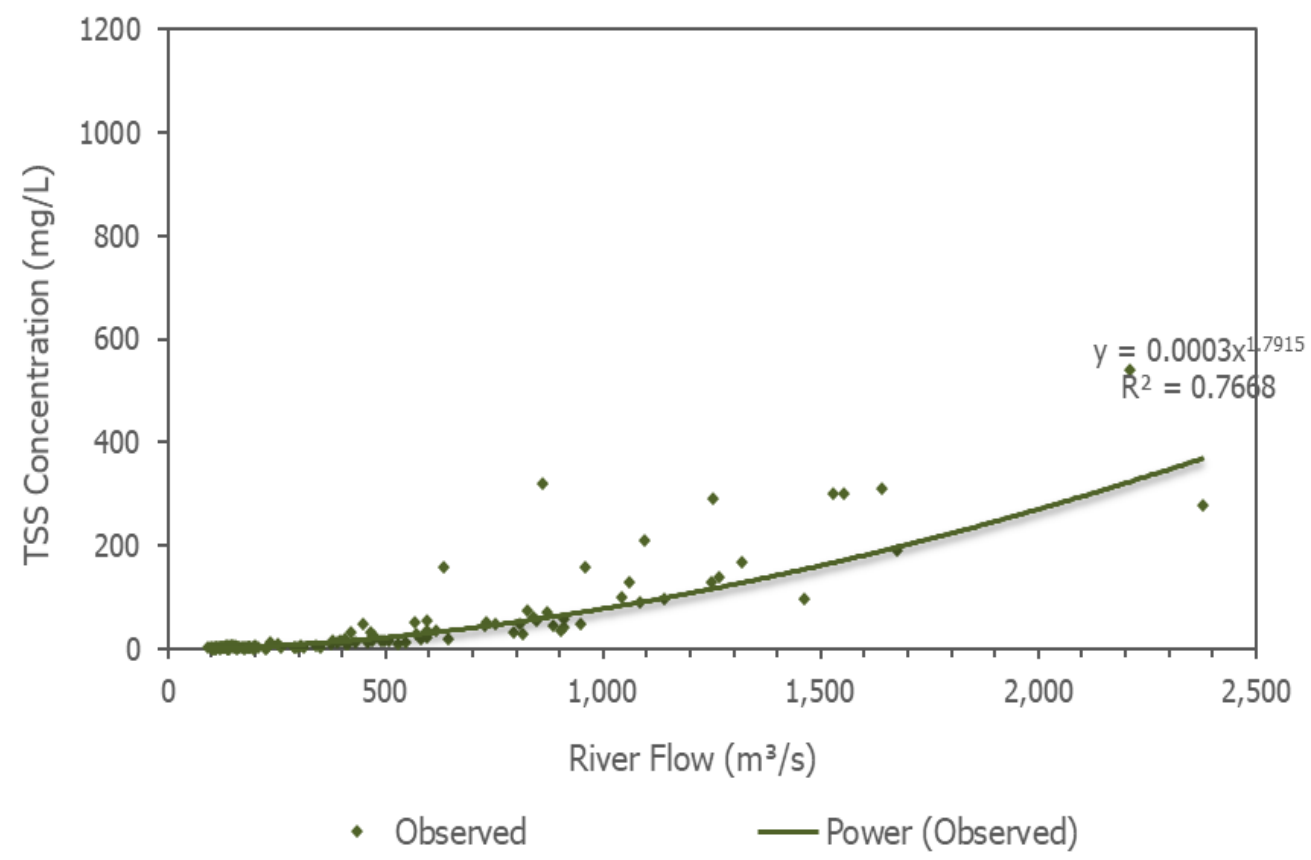

Figure A3. Total suspended sediment vs. flow for Athabasca River upstream of Firebag River.

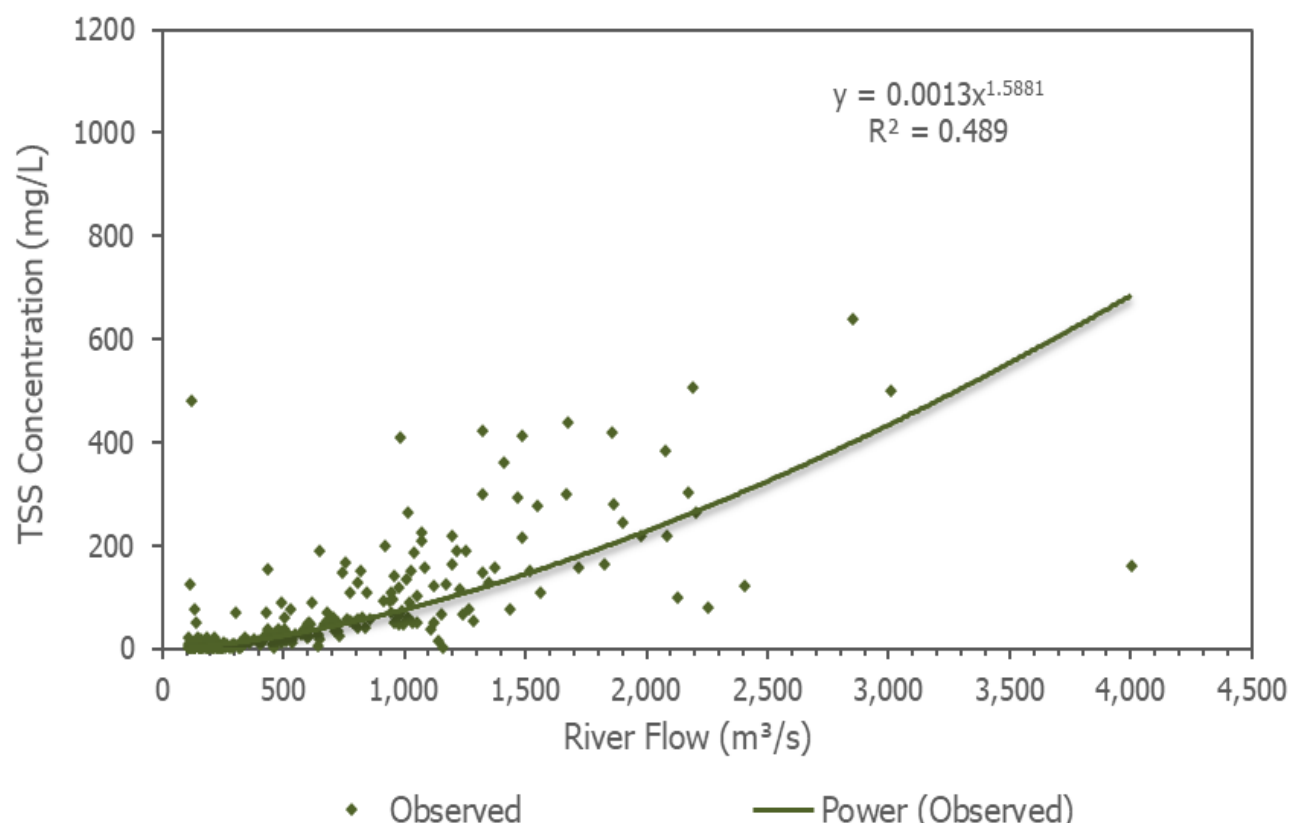

Figure A4. Total suspended sediment vs. flow for Athabasca River at Old Fort.

\section{References}

1. ECCC Canada-Alberta Joint Oil Sands Monitoring Program - Suspended Sediment Monitoring Disclaimer and Notes, Environment and Climate Change Canada, 2021. https://donnees.ec.gc.ca/data/substances/monitor/sediment-oil-sands-region/sediment-quality-mainstem-and-tributaries-oil-sands-region/?lang=en

2. Gupta, A.; Farjad, B.; Wang, G.; Eum, H.; Dubé, M. Integrated Environmental Modelling Framework for Cumulative Effects Assessment. University of Calgary Press, 2021.

3. Lindenschmidt, K.-E., Pech, I. and Baborowski, M. Environmental risk of dissolved oxygen depletion of diverted flood waters in river polder systems - a quasi-2D flood modelling approach. Science of the Total Environment 2009, 407(5), 1598-1612, http://dx.doi.org/10.1016/j.scitotenv.2008.11.024 
4. Lindenschmidt, K.-E. Quasi-2D approach in modelling the transport of contaminated sediments in floodplains during river flooding - model coupling and uncertainty analysis. Environmental Engineering Science 2008, 25(3), 333-352, http://www.liebertonline.com/doi/abs/10.1089/ees.2006.0192

5. Lindenschmidt, K.-E.; Huang, S.; Baborowski, M. A quasi-2D flood modelling approach to simulate substance transport in polder systems for environmental flood risk assessment. Science of the Total Environment 2008, 397(1-3), 86-102, http://dx.doi.org/10.1016/j.scitotenv.2008.02.045

6. Sehnert, C.; Lindenschmidt, K.-E. The effect of upstream river hydrograph characteristics on zinc deposition, dissolved oxygen depletion and phytoplankton growth in a flood detention basin system. Quaternary International 2009, 208, 158-168, http://dx.doi.org/10.1016/j.quaint.2008.09.013

7. Huang, S.; Vorogushyn, S.; Lindenschmidt, K.-E. Quasi 2D hydrodynamic modelling of the flooded hinterland due to dyke breaching on the Elbe River. Advances in Geosciences 2007, 11, 21-29, https://doi.org/10.5194/adgeo-11-21-2007

8. Huang, S.; Rauberg, J.; Apel, H.; Disse, M.; Lindenschmidt, K.-E. The effectiveness of polder systems on peak discharge capping of floods along the middle reaches of the Elbe River in Germany. Hydrology and Earth System Sciences 2007, 11, 1391-1401.

9. Sehnert, C.; Huang, S.; Lindenschmidt, K.-E. Quantifying structural uncertainty due to discretisation resolution and dimensionality in a hydrodynamic polder model. Journal of Hydroinformatics 2009, 11(1), 19-30, http://www.iwaponline.com/jh/011/0019/0110019.pdf

10. Cunge, J. A. Two-dimensional modeling of floodplains. In: Unsteady flow in open channels, Mahood, K., Yevjevich, V. Eds.; Water Resources Publications, Fort Collins, Colorado, USA, 1975, Volume 2, pp. 705-762.

11. Aureli, A.; Maranzoni, A.; Mignosa, P.; Ziveri, C. Flood hazard mapping by means of fully-2-D and quasi-2-D numerical modeling: a case study. In: Floods, from defence to management; van Alphen, J., van Beek, E., Taal, M. Eds.; $3^{\text {rd }}$ International Symposium on Flood Defence, Nijmegen, Netherlands, Taylor and Francis/Balkema, Blain, 2006; ISBN 0415391199, pp. 373-382.

12. Asselman, N. E. M.; Van Wijngaarden, M. Development and application of a 1-D floodplain sedimentation model for the River Rhine in the Netherlands. Journal of Hydrology 2002, 268, 127-142. http://dx.doi.org/10.1016/S0022-1694(02)00162-2

13. OSEM. Oil sands environmental monitoring, 2021, https://www.environment.alberta.ca/apps/OSEM/ (last accessed 31 July 2021)

14. Golder. Reach-specific water quality objectives for the lower Athabasca River. Prepared by Golder Associates Ltd. for Cumulative Environmental Management Association. Fort McMurray, Alberta, 2007.

15. Golder. Aquatic baseline report for the Athabasca, Steepbank and Muskeg Rivers in the vicinity of the Steepbank and Aurora Mines (Appendices). Prepared by Golder Associates Ltd. for Suncor Inc., May 1996.

16. Klohn-Crippon. Hydrology baseline for Project Millenium. Report PA 289.03 submitted to Suncor Energy Inc. by Klohn-Cippon 13 April 1998.

17. Newman, K.T. An integrated analysis of sediment geochemistry and flood history of floodplain lakes in the Athabasca Region. PhD thesis submitted to the University of Saskatchewan, 2019, https://harvest.usask.ca/handle/10388/12436

18. USACE. HEC-RAS River Analysis System - User's Manual Version 6.0. US Army Corps of Engineers Hydrologic Engineering Center, 2021. https://www.hec.usace.army.mil/software/hec-ras/documentation/HEC-RAS 6.0 Users Manual.pdf (last accessed 31 July 2021)

19. Dailey, J.E.; Harleman, D.R.F. Numerical model for the prediction of transient water quality in estuary networks. Report \# 158, RT72-72, Hydrodynamics Laboratory, Massachusetts Institute of Technology, Cambridge, MA., 1972.

20. Morse, B. St-Lawrence River water-levels study: Application of the ONE-D hydrodynamic model. Transport Canada, Waterways Development Div., Canadian Coast Guard, Ottawa, 1990.

21. Matte, P.; Secretan, Y.; Morin, J. Hydrodynamic modeling of the St. Lawrence fluvial estuary, 1: model setup, calibration and validation. Journal of Waterway, Port, Coastal, Ocean Engineering 2017, 143(5): 04017010. http://dx.doi.org/10.1061/(ASCE)WW.1943-5460.0000397

22. Sydor, M.; DeBoer, A.; Cheng, T. Developing a mathematical flow simulation model for the Peace-Athabasca delta. Environment Canada and Alberta Environment, Edmonton, Alberta, 1979, http://www.worldcat.org/oclc/70366515

23. Sydor, M.; Kassem, A.; Hamory, T. Evaluating potential implications of the proposed Devils Lake outlets on the quality of receiving water. Canadian Water Resources Association 55 ${ }^{\text {th }}$ Annual Conference, Winnipeg, Manitoba, 11 - 14 June 2002

24. Chowdhury, E.H.; Hassan, Q.K.; Achari, G.; Gupta, A. Use of Bathymetric and LiDAR Data in Generating Digital Elevation Model over the Lower Athabasca River Watershed in Alberta, Canada. Water 2017, 9(1), 19. https://doi.org/10.3390/W9010019

25. Fischer H.B.; List, J.E.; Koh, C.R.; Imberger, J.; Brooks, N.H. Mixing in Inland and Coastal Waters. Academic Press Inc., 1979.

26. Doneker, R.L.; Jirka, G.H. CORMIX User manual: a hydrodynamic mixing zone model and decision support system for pollutant discharges into surface waters, EPA-823-K-07-001, December 2007. Available for download at http://www.mixzon.com/downloads/

27. Trillium. Measurement of Transverse Mixing Coefficients in the lower Athabasca River. Prepared by Trillium Engineering and Hydrographics Inc. for the Cumulative Environmental Management Association (CEMA) Surface Water Working Group, 2003.

28. Golder. Athabasca River Model Update and Reach Segmentation. Prepared by Golder Associates Ltd. for Cumulative Environmental Management Association. Fort McMurray, Alberta, 2004.

29. Rosner, T.D. Athabasca River Model Documentation, 2021. Available online at https://fourelements.sharepoint.com/sites/AthabascaRiverModel

30. Ferguson, R.I.; Church, M.A. A simple universal equation for grain settling velocity. Journal of Sedimentary Research 2004, 74(6): 933. http://dx.doi.org/10.1306/051204740933 
31. RAMP. Regional Aquatics Monitoring Program in Support of the Joint Oil Sands Monitoring Plan. Final 2015 Program Report, April 2016. Prepared for Alberta Environmental Monitoring Evaluation and Reporting Agency by Hatfield Consultants, Kilgour and Associates Ltd., and Western Resource Solutions.

32. van Rijn, L.C. Unified View of Sediment Transport by Currents and Waves. I: Initiation of Motion, Bed Roughness, and BedLoad Transport. Journal of Hydraulic Engineering 2007, 133(6), 649-667, https://doi.org/10.1061/(ASCE)0733-9429(2007)133:6(649)

33. Dey, S.; Papanicolaou, A. Sediment threshold under stream flow: A state-of-the-art review. ASCE Journal of Civil Engineering 2008, 12(1): 45-60. https://doi.org/10.1007/s12205-008-8045-3

34. Maggi, F. The settling velocity of mineral, biomineral, and biological particles and aggregates in water. Journal of Geophysical Research: Oceans 2013, 118(4), 2118-2132, https://doi.org/10.1002/jgrc.20086 